\title{
PEDRO CALDERÓN DE LA BARCA
}

Un castigo en tres venganzas

\author{
EDICIÓN CRÍTICA DE \\ Margaret Rich Greer \\ y Francisco Sáez Raposo
}



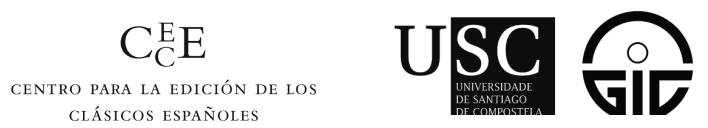

Cualquier forma de reproducción, distribución, comunicación pública o transformación de esta obra solo puede ser realizada con la autorización de sus titulares, salvo excepción prevista por la ley. Diríjase a CEDRO (Centro Español de Derechos Reprográficos) si necesita fotocopiar o escanear algún fragmento de esta obra (www.conlicencia.com; 917021970 / 9327204 47).

Reservados todos los derechos.

(C) Iberoamericana, 2018

Amor de Dios, 1 - E-28014 Madrid

Tel.: +34914293522

Fax: +34914295397

info@iberoamericanalibros.com

www.iberoamericana-vervuert.es

(C) Vervuert, 2018

Elisabethenstr. 3-9 - D-60594 Frankfurt am Main

Tel.: +49695974617

Fax: +49695978743

info@iberoamericanalibros.com

www.iberoamericana-vervuert.es

ISBN 978-84-9192-019-9 (Iberoamericana)

ISBN 978-3-95487-935-9 (Vervuert)

ISBN 978-3-95487-936-6 (e-book)

Depósito Legal: M-26488-2018

Cubierta: Carlos Zamora

Impreso en España

Este libro está impreso íntegramente en papel ecológico sin cloro. 


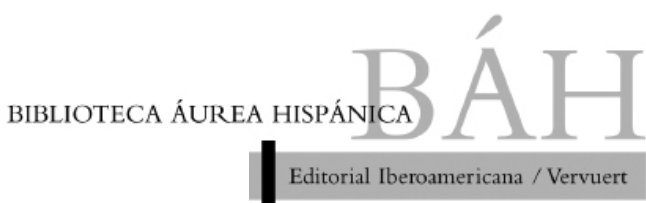

Dirección de Ignacio Arellano

Universidad de Navarra, Pamplona

con la colaboración de Christoph Strosetzki

Westfalische Wilhelms-Universität, Münster

y Marc Vitse

Université de Toulouse Le Mirail/Toulouse II

Subdirección:

Juan M. Escudero

Universidad de Navarra, Pamplona

Consejo asesor:

Patrizia Botta

Università La Sapienza, Roma

José María Díez Borque

Universidad Complutense, Madrid

Ruth Fine

The Hebrew University of Jerusalem

Edward Friedman

Vanderbilt University, Nashville

Aurelio González

El Colegio de México

Joan Oleza

Universidad de Valencia

Felipe Pedraza

Universidad de Castilla-La Mancha, Ciudad Real

Antonio Sánchez Jiménez

Université de Neuchâtel

Juan Luis Suárez

The University of Western Ontario, London

Edwin Williamson

University of Oxford

Biblioteca Áurea Hispánica, 122 Comedias completas de Calderón, 20 
